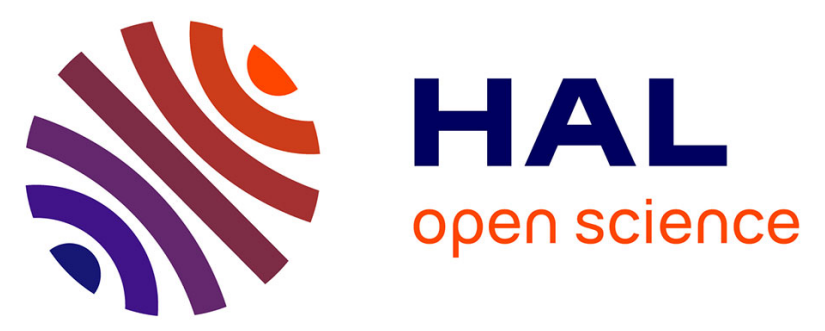

\title{
Synthesis and palladium-catalysed isomerisation of fused polycyclic tetrahydrofurans : efficient and stereoselective one-pot domino construction of functionalised bridged bicyclo[n.2.1] ring systems
}

Pierre-Yves Roger, Fabien Blondeau, David Bensa, Thierry Constantieux, Jean Rodriguez

\section{To cite this version:}

Pierre-Yves Roger, Fabien Blondeau, David Bensa, Thierry Constantieux, Jean Rodriguez. Synthesis and palladium-catalysed isomerisation of fused polycyclic tetrahydrofurans: efficient and stereoselective one-pot domino construction of functionalised bridged bicyclo[n.2.1] ring systems. Molecular Diversity, 2009, 13, pp.469-473. 10.1007/s11030-009-9131-2 . hal-00681054

\author{
HAL Id: hal-00681054 \\ https://hal.science/hal-00681054
}

Submitted on 20 Mar 2012

HAL is a multi-disciplinary open access archive for the deposit and dissemination of scientific research documents, whether they are published or not. The documents may come from teaching and research institutions in France or abroad, or from public or private research centers.
L'archive ouverte pluridisciplinaire HAL, est destinée au dépôt et à la diffusion de documents scientifiques de niveau recherche, publiés ou non, émanant des établissements d'enseignement et de recherche français ou étrangers, des laboratoires publics ou privés. 


\title{
Synthesis and palladium-catalysed
}

\section{isomerisation of fused polycyclic}

tetrahydrofurans: Efficient and

stereoselective one-pot domino construction

of functionalised bridged bicyclo[n.2.1] ring

\section{systems}

Pierre-Yves Roger, Fabien Blondeau, David Bensa, Thierry Constantieux* and Jean Rodriguez*

Aix-Marseille Université - Institut des Sciences Moléculaires de Marseille UMR

CNRS 6263 iSm2 ; Centre Saint Jérôme, service 531 ; 13397, Marseille cedex 20, France.

Tel : +33-(0)491-282-874

Fax : +33-(0)491-286-187

Email : jean.rodriguez@univ-cezanne.fr; thierry.constantieux@univ-cezanne.fr

Web site : www.ism2.univ-cezanne.fr

\begin{abstract}
A new one-pot domino reaction for a general entry to functionalised bridged bicyclo[n.2.1] ring systems from $\alpha, \alpha^{\prime}$-diactivated cyclic ketones and trans-1,4-dihalides is described. The sequence combines a base promoted C-O cycloalkylation reaction leading to fused polycyclic enol ethers and their in situ palladium-catalysed isomerisation.
\end{abstract}

Keywords vinyltetrahydrofurans; palladium-catalysed isomerisation; bicyclo[2.2.1] heptanone; bicyclo[3.2.1] octanone; bicyclo[4.2.1] nonanone.

\section{Introduction}

Polysubstituted bridged bicyclo[n.2.1] ring systems are important substructures present in a large variety of natural bioactive compounds [1-4]. Moreover these derivatives, when properly functionalised, may constitute powerful building blocks and useful reactive intermediates in stereoselective synthetic strategies. 
Although several conventional approaches for the synthesis of these valuable bicyclic skeletons have been reported [5-6], the development of conceptually new methods still remains an academic challenge. In this context, one-pot sequential and domino reactions [7] have emerged as modern synthetic powerful tools [8-9] because of significant advantages, such as high atom-economy [10-11], bondforming efficiency [12-13], selectivity, molecular complexity and diversity [1416], and environmental prevency. In this family, domino reactions of monoanions [17], dianions and masked dianion equivalents [18-19] derived from $\beta$-dicarbonyl compounds have been extensively studied. However, in spite of the synthetic usefulness of these systems, the synthetic potential of anions derived from readily available 1,3-diactivated ketones has been less explored [20-21].

In the course of our studies on the reactivity of stabilised carbanions derived from acyclic and cyclic 1,3-ketodicarboxylates for the regio-, chemo- and stereoselective formation of carbon-carbon and carbon-oxygen bonds, we reported a facile base-promoted one-pot preparation of functionalised bridged bicyclo[n.2.1]alkanones and fused polycyclic functionalised enol ethers [22-23]. The latter compounds, containing a 2-vinyl- or 2-vinylidene function, are known to undergo a variety of rearrangements including thermal [24-26] or palladiumcatalysed [27-29] skeletal reorganisation to cycloheptenones or cyclopentenones. As an illustration of these synthetic potentialities, we reported an efficient construction of functionalised bridged bicyclo[4.n.1] ring systems via thermal Claisen rearrangement of such fused polycyclic tetrahydrofurans [30]. In this paper we present a new one-pot domino reaction for a general entry to functionalised bridged bicyclo[n.2.1] ring systems from $\alpha, \alpha^{\prime}$-diactivated cyclic ketones and trans-1,4-dihalides. The sequence combines a base promoted C-O cycloalkylation reaction leading to fused polycyclic enol ethers and their in situ palladium-catalysed isomerisation, and constitutes a good complement to the previously reported thermal Claisen rearrangement in terms of molecular complexity and diversity.

\section{Results and discussion}

As previously described [23], the condensation promoted by $\mathrm{K}_{2} \mathrm{CO}_{3}$ in refluxing THF between easily available cyclic 1,3-diactivated ketones and trans-1,4- 
dibromobutene allows the one-pot construction of 2-vinyl-hexahydro-2,3benzofuran derivatives, which are obtained with very high chemical purity after a simple filtration through a short pad of celite. On the basis of work by Tsuji [27] and Trost [28], we thought that these polycyclic enol ethers, from the five- to seven-membered ring series, could be involved in a palladium-catalysed rearrangement leading to highly functionalised bicyclo[n.2.1]alkanones (Scheme 1). Recently, a similar approach was developed by Langer et al, who succeeded by this way in the stereoselective preparation of bicyclo[3.2.1]octan-8-ones [31]. Thus, we were pleased to note that treatment of compounds 2a-d in DMSO at 80 ${ }^{\circ} \mathrm{C}$, in the presence of $5 \mathrm{~mol} \%$ of $\operatorname{Pd}(\mathrm{dppe})_{2}$, resulted after a few hours in the formation of the desired bicyclo[n.2.1]alkanones derivatives 3a-d (Table 1). The products were obtained with good to high yields as a separable endo/exo mixture, in proportion ranging from $1: 1$ to $2: 1$.

On the basis of these good results, and due to the mild basic conditions applied for the facile preparation of the starting polycyclic enol ethers, we envisioned to develop a one-pot domino sequence leading to the bicyclo[n.2.1]alkanones directly from the $\alpha, \alpha^{\prime}$-diactivated ketone (Scheme 2 ). Thus, ketones 1a-d were reacted with trans-1,4-didromobutene at $80{ }^{\circ} \mathrm{C}$ in DMSO in the presence of $\mathrm{K}_{2} \mathrm{CO}_{3}$, and the reaction was monitored by TLC analysis. After complete conversion of the starting material, a catalytic amount of $\mathrm{Pd}(\mathrm{ddpe})_{2}$ was added in order to in situ isomerise the intermediate enol ether. For our great pleasure, the desired bridged bicycloalkanones 3a-d were formed with good to high yields comparable with those observed in the two steps procedure, and stereoselectivity was slightly improved in favour of the endo isomer.

In conclusion, this domino transformation illustrates the synthetic potential of stabilised carbanions derived from cyclic 1,3-ketodicarboxylates. This userfriendly procedure involving very mild reaction conditions constitutes a good alternative to other more conventional methods reported for the preparation of bicyclo[n.2.1]alkanones. Molecular diversity can be easily accessed since same starting enol ether may lead either to bridged bicyclo[4.n.1] or bicyclo[n.2.1] ring systems depending on the thermal or metal-catalysed method of isomerisation used.

\section{Material and methods}


All purchased solvents and chemicals were analytical grade and used without further purification. ${ }^{1} \mathrm{H}$-NMR and ${ }^{13} \mathrm{C}$-NMR spectra were recorded in solution respectively at $300.13 \mathrm{MHz}$ and $75.47 \mathrm{MHz}$ on a Bruker AC 300 spectrometer. NMR data were collected at ambient temperature, and chemical shifts were given in ppm referenced to the appropriate solvent peak. Data for ${ }^{1} \mathrm{H}$ NMR are reported as follows: chemical shift, integration, multiplicity $(\mathrm{br}=$ broad, $\mathrm{s}=$ singlet, $\mathrm{d}=$ doublet, $\mathrm{t}=$ triplet, $\mathrm{q}=$ quadruplet, $\mathrm{dd}=$ doublet of doublets, $\mathrm{m}=$ multiplet). Infrared (IR) spectra were recorded on a Perkin-Elmer 1600 Series FTIR spectrometer. Analytical thin layer chromatography was performed using 0.20 mm silica gel 60 plates. Flash chromatography was performed using 70-230 mesh silica gel 60 (Merck).

General procedure for the palladium-catalysed isomerisation of 2-vinylhexahydro-2,3-benzofuran derivatives:

In a Schlenk tube flushed with Ar and equipped with a magnetic stirring bar were introduced the polycyclic enol ether $2(1.6 \mathrm{mmol})$ and freshly distilled DMSO (10 $\mathrm{mL})$. The solution was then degazed, before introduction of $\mathrm{Pd}(\mathrm{ddpe})_{2}(0.08$ mmol, $5 \mathrm{~mol} \%$ ). The reaction mixture was strirred at $80{ }^{\circ} \mathrm{C}$ and monitored by TLC analysis. The colour changed from red to black. After total isomerisation of the starting material, the solution was cooled to room temperature and $20 \mathrm{~mL}$ of $\mathrm{Et}_{2} \mathrm{O}$ were added. After filtration over a pad of celite, the organic phase was washed with $3 \times 10 \mathrm{~mL}$ of water, and dried over sodium sulphate. Finally, evaporation of volatiles afforded a crude mixture of endo- and exobicyclo[n.2.1]alkanones, which were separated and purified by flash chromatography.

General procedure for the one-pot synthesis of bicyclo[n.2.1]alkanones 3 from $\alpha, \alpha^{\prime}$-diactivated ketone $\mathbf{1}$ :

In a Schlenk tube flushed with Ar and equipped with a magnetic stirring bar were introduced the $\alpha, \alpha^{\prime}$-diactivated ketone 1 (2.0 mmol), (E)-1,4-dibromobut-2-ene (2.0 mmol), $\mathrm{K}_{2} \mathrm{CO}_{3}(6.0 \mathrm{mmol})$ and freshly distilled DMSO $(10 \mathrm{~mL})$. The solution 
was degased, and then strirred at $80{ }^{\circ} \mathrm{C}$ while monitored by TLC analysis. After total conversion of the starting material, $\mathrm{P}(\text { ddpe })_{2}(0.1 \mathrm{mmol}, 5 \mathrm{~mol} \%)$ was added, and stirring at $80{ }^{\circ} \mathrm{C}$ was continued until total isomerisation of the enol intermediate (TLC monitoring). The solution was then cooled to room temperature and $20 \mathrm{~mL}$ of $\mathrm{Et}_{2} \mathrm{O}$ were added. After filtration over a pad of celite, the organic phase was washed with $3 \times 10 \mathrm{~mL}$ of water, and dried over sodium sulphate. Finally, evaporation of volatiles afforded a crude mixture of endo- and exo- bicyclo[n.2.1]alkanones, which were separated and purified by flash chromatography.

2a,4a-dimethylcarboxylate-1-vinyl-bicyclo[2.2.1] heptan-7-one $3 \boldsymbol{a}$

Colourless viscous oil. $\mathrm{R}_{\mathrm{f}}=0.50$ (diethyl ether/petroleum ethers: $1 / 1$ ); Anal. calcd (\%) for $\mathrm{C}_{13} \mathrm{H}_{16} \mathrm{O}_{5}$ : C, 61.90; $\mathrm{H}, 6.39 ; \mathrm{O}, 31.71$; Found (\%): C, 61.87; H, 6.37; O, 31.75. MS (ESI): $m / z(\%)=253(100)\left[\mathrm{M}+\mathrm{H}^{+}\right]$.

endo isomer: ${ }^{1} \mathrm{H}$ NMR (300 Mhz, $\left.\mathrm{CHCl}_{3}\right)$ : $\delta=1.73-2.59(\mathrm{~m}, 6 \mathrm{H}), 2.83-2.97(\mathrm{~m}$, $1 \mathrm{H}), 3.75(\mathrm{~s}, 6 \mathrm{H}), 4.90-5.40(\mathrm{~m}, 2 \mathrm{H}), 5.60-5.96(\mathrm{~m}, 1 \mathrm{H}) .{ }^{13} \mathrm{C} \mathrm{NMR}(75 \mathrm{MHz}$, $\left.\mathrm{CDCl}_{3}\right): \delta=19.6,27.0,32.3,38.6,52.4(2 \mathrm{C}), 58.2,59.6,118.7,135.1,169.2$, 169.6, 201.

exo isomer: ${ }^{1} \mathrm{H}$ NMR $\left(300 \mathrm{Mhz}, \mathrm{CHCl}_{3}\right): \delta=1.73-2.59(\mathrm{~m}, 6 \mathrm{H}), 2.83-2.97(\mathrm{~m}$, $1 \mathrm{H}), 3.75(\mathrm{~s}, 6 \mathrm{H}), 4.90-5.40(\mathrm{~m}, 2 \mathrm{H}), 5.60-5.96(\mathrm{~m}, 1 \mathrm{H}) .{ }^{13} \mathrm{C} \mathrm{NMR}(75 \mathrm{MHz}$, $\left.\mathrm{CDCl}_{3}\right): \delta=23.7,31.2,35.4,43.6,52.0,52.8,54.7,58.5,116.9,137.1,173.8$, $174.3,200.3$.

2a,5a-dimethylcarboxylate-1-vinyl-bicyclo[3.2.1]octane-8-one $\mathbf{3 b}$

Colourless viscous oil. $\mathrm{R}_{\mathrm{f}}=0.41$ (diethyl ether/petroleum ethers: 1/1); Anal. calcd (\%) for $\mathrm{C}_{14} \mathrm{H}_{18} \mathrm{O}_{5}$ : C, 63.15; H, 6.81; O, 30.04; Found (\%): C, 63.11; H, 6.79; O, 30.09. MS (ESI): $m / z(\%)=267(100)\left[\mathrm{M}+\mathrm{H}^{+}\right]$.

endo isomer: ${ }^{1} \mathrm{H}$ NMR (300 Mhz, $\left.\mathrm{CHCl}_{3}\right)$ : $\delta=1.65-2.45(\mathrm{~m}, 8 \mathrm{H}), 2.80-2.95(\mathrm{~m}$, $1 \mathrm{H}), 3.75(\mathrm{~s}, 6 \mathrm{H}), 5.20-5.34(\mathrm{~m}, 2 \mathrm{H}), 5.87-6.03(\mathrm{~m}, 1 \mathrm{H}) .{ }^{13} \mathrm{C} \mathrm{NMR}(75 \mathrm{MHz}$, $\left.\mathrm{CDCl}_{3}\right): \delta=17.6,31.6,33.6,38.6,40.4,52.5$ (2C), 59.1, 62.7, 118.4, 134.4, 170.3, $170.7,208.5$. 
exo isomer: ${ }^{1} \mathrm{H}$ NMR $\left(300 \mathrm{Mhz}, \mathrm{CHCl}_{3}\right): \delta=1.73-2.59(\mathrm{~m}, 8 \mathrm{H}), 2.83-2.97(\mathrm{~m}$, $1 \mathrm{H}), 3.65(\mathrm{~s}, 3 \mathrm{H}), 3.74(\mathrm{~s}, 3 \mathrm{H})$ 4.90-5.05 (m, 2H), 5.66-5.79 (m, 1H). ${ }^{13} \mathrm{C} \mathrm{NMR}$ $\left(75 \mathrm{MHz}, \mathrm{CDCl}_{3}\right): \delta=17.5,34.3,38.8,39.8,45.0,51.7,52.4,59.7,62.1,115.1$, 139.2, 169.6, 170.7, 208.8 .

2a,5a-dimethylcarboxylate-4-methylene-1-vinyl-bicyclo[3.2.1]octane-8-one 3c

Colourless viscous oil. $\mathrm{R}_{\mathrm{f}}=0.65$ (diethyl ether/petroleum ethers: $1 / 1$ ); Anal. calcd (\%) for $\mathrm{C}_{15} \mathrm{H}_{18} \mathrm{O}_{5}$ : C, 64.74; H, 6.52; O, 28.74; Found (\%): C, 64.71; H, 6.49; O, 28.78. MS (ESI): $m / z(\%)=279(100)\left[\mathrm{M}+\mathrm{H}^{+}\right]$.

endo isomer: ${ }^{1} \mathrm{H}$ NMR (300 Mhz, $\left.\mathrm{CHCl}_{3}\right)$ : $\delta=1.80-1.92(\mathrm{~m}, 2 \mathrm{H}), 2.65-3.07(\mathrm{~m}$, $5 \mathrm{H}), 3.68(\mathrm{~s}, 3 \mathrm{H}), 3.76(\mathrm{~s}, 3 \mathrm{H}), 5.03-5.20(\mathrm{~m}, 4 \mathrm{H}), 5.85-6.00(\mathrm{~m}, 1 \mathrm{H}) .{ }^{13} \mathrm{C} \mathrm{NMR}$ $\left(75 \mathrm{MHz}, \mathrm{CDCl}_{3}\right): \delta=32.7,40.6,41.9,46.5,52.6$ (2C), 58.1, 62.6, 102.1, 117.2, 118.9, 134.3, 169.7, 170.2, 207.9.

exo isomer: ${ }^{1} \mathrm{H}$ NMR $\left(300 \mathrm{Mhz}, \mathrm{CHCl}_{3}\right): \delta=2.05-2.35(\mathrm{~m}, 2 \mathrm{H}), 2.45-3.15(\mathrm{~m}$, $5 \mathrm{H}), 3.66(\mathrm{~s}, 3 \mathrm{H}), 3.75(\mathrm{~s}, 3 \mathrm{H}), 4.80-5.70(\mathrm{~m}, 4 \mathrm{H}), 5.65-5.85(\mathrm{~m}, 1 \mathrm{H}) .{ }^{13} \mathrm{C} \mathrm{NMR}$ $\left(75 \mathrm{MHz}, \mathrm{CDCl}_{3}\right): \delta=34.7,45.4,46.4,47.5,51.9,52.6,59.0,61.4,102.0,115.5$, 117.6, 138.8, 169.1, 170.2, 208.2.

2a,8a-dimethylcarboxylate-1-vinyl-tricyclo[8.2.1.0 $\left.0^{3 a, 7 a}\right]$ trideca-3a(7a),4,6-trien-9one $3 \boldsymbol{d}$

Colourless viscous oil. $\mathrm{R}_{\mathrm{f}}=0.67$ (diethyl ether/petroleum ethers: 1/1); Anal. calcd (\%) for $\mathrm{C}_{19} \mathrm{H}_{20} \mathrm{O}_{5}$ : C, 69.50; H, 6.14; O, 24.36; Found (\%): C, 69.45; H, 6.11; O, 24.43. MS (ESI): $m / z(\%)=329(100)\left[\mathrm{M}+\mathrm{H}^{+}\right]$.

endo/exo mixture: ${ }^{1} \mathrm{H}$ NMR (300 Mhz, $\left.\mathrm{CHCl}_{3}\right): \delta=1.28-1.57(\mathrm{~m}, 2 \mathrm{H}), 2.27-2.71$ $(\mathrm{m}, 1 \mathrm{H}), 2.75-3.54(\mathrm{~m}, 3 \mathrm{H}), 3.76(\mathrm{~s}, 6 \mathrm{H}) / 3.82$ and $3.86(\mathrm{~s}, 3 \mathrm{H}), 4-80-4.95 / 4.95-$ $5.08(\mathrm{dd}, J=15 \mathrm{~Hz}, J=9 \mathrm{~Hz}, 2 \mathrm{H}), 5.35-5.50 / 5.70-5.85(\mathrm{ddd}, J=15 \mathrm{~Hz}, J=9 \mathrm{~Hz}$, $J=6 \mathrm{~Hz}, 1 \mathrm{H}), 7.02-7.40(\mathrm{~m}, 5 \mathrm{H}) .{ }^{13} \mathrm{C} \mathrm{NMR}\left(75 \mathrm{MHz}, \mathrm{CDCl}_{3}\right): \delta=33.7 / 35.7$, $38.1 / 42.3,42.5 / 42.9, \quad 44.5 / 45.5,52.2 / 52.8, \quad 52.9 / 53.0,59.3 / 61.1,64.7 / 64.8$, $115.8 / 118.6, \quad 127.5 / 127.6, \quad 128.0, \quad 132.1 / 132.3, \quad 132.5 / 132.7, \quad 134.7 / 138.9$, 135.7/136.0, 136.2, 170.1/170.9, 171.4/171.6, 211.7/212.8.

Acknowledgements The authors would like to thank the Université Paul Cézanne and the CNRS for financial support. P-Y. R. acknowledges The Ministère de 1'Enseignement Supérieur et de la 
Recherche for the award of a doctoral fellowship. Pr. Max Malacria, University Paris VI, is also sincerely acknowledged for interesting suggestions and discussions on palladium chemistry.

\section{References}

1. Heathcock CH, Graham SL, Pirrung MC, Plavac F, White CT (1982) The total synthesis of natural products, Vol. 5, Apsimon JW Ed, Wiley, New-York.

2. Hanson JR (1983) Terpenoids and steroids, Vol. 12, The Royal Society of Chemistry, London.

3. Yamamura S, Shizuri Y, Shigemori H, Okuno Y, Ohkubo M (1991) Natural products syntheses using anodic oxidation of phenols as a key step. Tetrahedron 47:635-644.

4. Mander LN (1992) The chemistry of gibberellins: an overview. Chem. Rev. 92: 573612.

5. Casanova J, Koukoua G, Waegell B (1990) Bicyclo[4.2.1]nonane skeleton. Conformational analysis, synthesis, reactivity. Bull. Soc. Chim. Fr. 127: 528-552.

6. Filippini MH, Rodriguez J (1999) Synthesis of functionalized bicyclo[3.2.1]octanes and their multiple uses in organic chemistry. Chem. Rev. 99: 27-76.

7. Tietze LF, Brasche G, Gericke KM (2006) Domino Reactions in Organic synthesis. Wiley-VCH, Weinheim.

8. Wender PA, Handy ST, Wright DL (1997) Toward the ideal synthesis. Chem. Ind. 765-769.

9. Wender PA, Baryza JL, Brenner SE, Clarke MO, Gamber GG, Horan JC, Jessop TC, Kan C, Pattabiraman K, Williams TJ (2003) Inspirations from nature: new reactions, therapeutic leads, and drug delivery systems. Pure Appl. Chem. 75: 143-155.

10. Trost BM (1991) The atom economy - a search for synthetic efficiency. Science 254: 1471-1477.

11. Trost BM (2002) On inventing reactions for atom economy. Acc. Chem. Res. 35: 695-705.

12. Wender PA, Bi FC, Gamber GG, Gosselin F, Hubbard RD, Scanio MJC, Sun R, Williams TJ, Zhang L (2002) Toward the ideal synthesis. New transition metalcatalyzed reactions inspired by novel medicinal leads. Pure Appl. Chem. 74: 25-31.

13. Wender PA, Gamber GG, Hubbard RD, Pham SM, Zhang L (2005) Multicomponent cycloadditions: The four-component $[5+1+2+1]$ cycloaddition of vinylcyclopropanes, alkynes, and CO. J. Am. Chem. Soc. 127: 2836-2837.

14. Schreiber SL (2000) Target-oriented and diversity-oriented organic synthesis in drug discovery. Science 287: 1964-1969.

15. Vugts DJ, Koningstein MM, Schmitz RF, de Kanter FJJ, Groen MB, Orru RVA (2006) Multicomponent synthesis of dihydropyrimidines and thiazines. Chem. Eur. J. 7178-7189.

16. Nielsen TE, Schreiber SL (2008) Towards the optimal screening collection: A synthesis strategy. Angew. Chem. Int. Ed. 47: 48-56. 
17. Wang T, Chen J, Zhao K (1995) 1,3-Diastereocontrolled O-displacement of enolates. J. Org. Chem., 60:2668-2669.

18. Langer P. (2001) Regio- and diastereoselective cyclization reactions of free and masked 1,3-dicarbonyl dianions with 1,2-dielectrophiles. Chem. Eur. J. 3859-3866.

19. Langer P., Freiberg W (2004) Cyclization reactions of dianions in organic synthesis. Chem. Rev. 104: 4125-4149.

20. Bates RB, Taylor SR (1994) Dialkylation of ketone dianions. J. Org. Chem. 59: 245246.

21. Lee SY, Lee CW, Oh DY (2000) Regiocontrolled synthetic approach to $\alpha, \alpha^{\prime}-$ disubstituted unsymmetrical ketones. J. Org. Chem. 65: 245-248.

22. Lavoisier-Gallo T, Rodriguez J (1997) Facile one-pot preparation of functionalized 2vinylidenehydrofurans by tandem C-O-cycloalkylation of stabilized carbanions. J. Org. Chem. 62: 3787-3788.

23. Lavoisier-Gallo T, Charonnet E, Pons JM, Rajzman M, Faure R, Rodriguez J (2001) C-C versus C-O anionic domino cycloalkylation of stabilized carbanions: facile onepot stereoselective preparation of functionalized bridged bicycloalkanones ans cyclic enol ethers. Chem. Eur. J. 7: 1056-1068.

24. Rhoads SJ, Watson JM (1971) The Claisen rearrangement of 2-methyl-2-vinyl-5methylenetetrahydrofuran. J. Am. Chem. Soc. 93:5813-5815.

25. Marvell EN, Titterington D (1980) A novel synthesis of 4-cycloheptenones. Tetrahedron Lett. 21: 2123-2124.

26. Montalt J, Linker F, Ratel F, Miesch M (2004) Synthesis of bicyclo[4.n.1]alkanones. J. Org. Chem. 69: 6715-6721.

27. Tsuji J, Kobayashi Y, Kataoka H, Takahashi T (1980) Preparation of five- and sixmembered cyclic ketones by the palladium-catalyzed cyclisation reaction. Application to methyl dihydrojasmonate synthesis. Tetrahedron Lett. 21: 1475-1478.

28. Trost BM, Runge TA (1981) Palladium-catalyzed 1,3-oxygen-to-carbon alkyl shifts. Basic studies. J. Am. Chem. Soc. 103: 7550-7559.

29. Ghobsi A, Hacini S, Wavrin L, Gaudel-Siri A, Corbères A, Nicolas C, Bonne D, Viala, Rodriguez J. (2008) Palladium-catalysed isomerisation of 2vinylidenehydrofurans to 1,3-dienes and some aspects of their reactivity Eur. J. Org. Chem. 4446-4453.

30. Lavoisier-Gallo T, Charonnet E, Rodriguez J (1997) Thermal Claisen rearrangement of fused polycyclic tetrahydrofurans. A new efficient efficient construction of functionalized bridged bicyclo[4.n.1] ring systems. Synthesis 1258-1260.

31. Langer P, Holtz E, Saleh NNR (2002) Efficient and stereoselective synthesis of bicycle[3.2.1] octan-8-ones: synthesis and palladium-catalyzed isomerisation of functionalized 2-vinyl-2,3,3a,4,5,6-hexahydro-2,3-benzofurans. Chem. Eur. J. 8: 917928. 


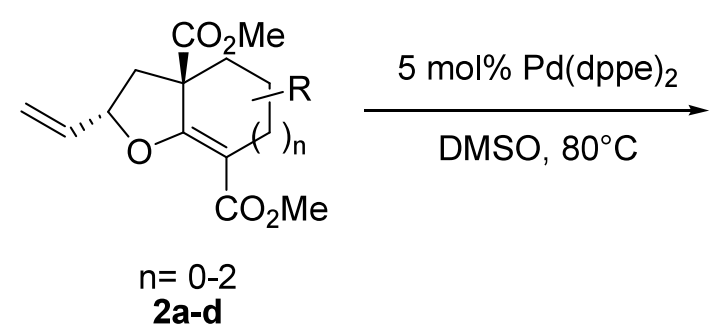

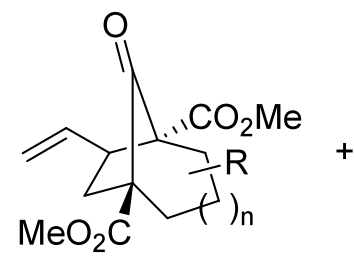

exo-3a-d

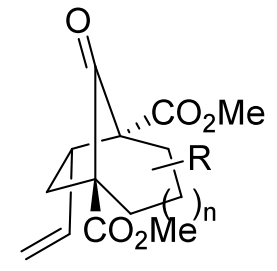

endo-3a-d

Scheme 1 Palladium-catalysed rearrangement of 2-vinyl-hexahydro-2,3-benzofuran derivatives

Table 1 Synthesis of bicyclo[n.2.1]alkanones 3a-d from 2-vinyl-hexahydro-2,3-benzofurans 2a-d

Entry time

${ }^{\mathrm{a}}$ Isolated yield after flash chromatography 

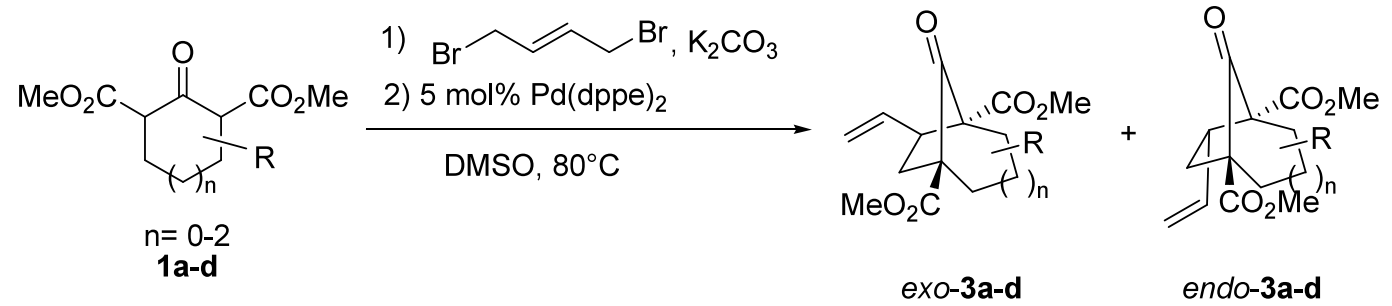

Scheme 2 One-pot domino reaction for the synthesis of bicyclo[n.2.1]alkanones 3a-d

Table 1 One-pot synthesis of bicyclo[n.2.1]alkanones 3a-d from $\alpha, \alpha^{\prime}$-diactivated ketones 1a-d

\begin{tabular}{|c|c|c|c|c|c|}
\hline Entry & Substrate 1 & time & $\begin{array}{c}\text { Product } \\
\mathbf{3}\end{array}$ & $\begin{array}{c}\text { Yield }^{\mathrm{a}} \\
(\%)\end{array}$ & endo/exo \\
\hline 1 & la & $\begin{array}{c}2 \mathrm{~h} \\
+ \\
2 \mathrm{~h}\end{array}$ & $3 \mathbf{a}$ & 85 & $2 / 1$ \\
\hline 2 & 4 & $\begin{array}{c}5 \mathrm{~h} \\
+ \\
3 \mathrm{~h}\end{array}$ & $3 b$ & 82 & $2.5 / 1$ \\
\hline 3 & $\mathrm{CO}_{2} \mathrm{M}$ & $\begin{array}{c}5 \mathrm{~h} \\
+ \\
6 \mathrm{~h}\end{array}$ & $3 c$ & 65 & $2.5 / 1$ \\
\hline 4 & 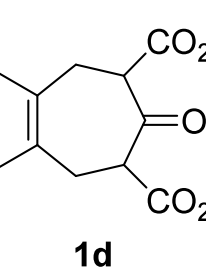 & $\begin{array}{c}5 \mathrm{~h} \\
+ \\
2 \mathrm{~h}\end{array}$ & 3d & 87 & $2.5 / 1$ \\
\hline
\end{tabular}

${ }^{\mathrm{a}}$ Isolated yield after flash chromatography 